Title: Empowering young people who experienced domestic violence and abuse: the development of a group therapy intervention

Authors:

Lisa C. Fellin, University of East London

Jane E.M. Callaghan, Centre for Child Wellbeing and Protection, University of Stirling Joanne H. Alexander, University of Northampton

Claire Harrison-Breed, University of Northampton

Stavroula Mavrou, Aristotle University Thessaloniki

Maria Papathanasiou, Aristotle University Thessaloniki

Running Title: MPOWER

Corresponding Author Jane.E.M. Callaghan, Centre for Child Wellbeing and Protection, University of Stirling, Stirling, FK9 4LA

Jane.callaghan@stir.ac.uk

Accepted: Clinical Child Psychology and Psychiatry.

Fellin LC, Callaghan JEM, Alexander JH, Harrison-Breed C, Mavrou S \& Papathanassiou M, Empowering young people who experienced domestic violence and abuse: the development of a group therapy intervention, Clinical Child Psychology (Volume 24, Issue 1), pp. 170-189. Copyright (C) Authors 2018. Reprinted by permission of SAGE Publications.. 


\title{
Empowering young people who experienced domestic violence and abuse: the development of a group therapy intervention
}

\begin{abstract}
This article describes the development of a group based therapeutic intervention for young people (YP) who have lived with domestic violence and abuse. The intervention was informed by interviews with $107 \mathrm{YP}$, focused on their experiences of coping, resilience and agency. The intervention draws on resources from systemic, creative and narrative approaches to group work, and aims to facilitate YP's expression of distress in a way that recognises that it is embodied, contextual and relational. The intervention also explores YPs' existing strategies for coping and maintaining a sense of agency, and works to harness, enhance and further develop those skills. We report on the pilot of this intervention, and its development and application across four European countries (UK, Greece, Italy and Spain). We outline the goals, strengths and limitations of this group intervention, as well as the main challenges, hindrances and ethical dilemmas experienced the research and intervention team. Implications for therapeutic practice and training are addressed.
\end{abstract}




\section{Introduction}

Children who live with family violence are often described in academic and practitioner literature as a 'vulnerable' group, but there are very few services that offer targeted support for these young people. Radford, Corral, Bradley and Fisher (2013) found that almost 30\% of children and young people (YP) have been exposed to domestic violence and abuse (DVA) during their lifetime, with often severe and long-term impacts on their personal and social development (Wood \& Sommers, 2011). Despite evidence of extensive mental health need amongst YP affected by DVA (Meltzer, Doos, Vostanis, Ford, \& Goodman, 2009), in the UK, only $9-11 \%$ of YP receive support from Child and Adolescent Mental Health Services (CAMHS) (CAADA, 2014). Access to CAMHS is largely driven by psychiatric diagnosis, and because DVA is often seen as a social problem, this can function as a barrier to their access (Callaghan, Fellin \& Warner-Gale, 2017).

One challenge in meeting the needs of YP affected by DVA is a lack of evidence based, accessible and appropriate interventions. Domestic abuse organisations favour group interventions as they are usually cost-effective and well received by YP (Bunston, 2008; Bunston et al., 2016). However, there is limited evidence for their effectiveness, as few good quality trials have been conducted (Howarth et al., 2016). Nonetheless, it is clear that some level of therapeutic intervention with YP is important: for example, Jenny and Alaggia 2012 (cited in Ungar, 2016) reported that YP who experienced DVA and received adequate support appeared to function as effectively as their peers.

The group interventions that are available often target young people's relationships with non-violent parents (Smith, 2016), or focus on preventing young people from using violence and abuse themselves in their interpersonal relationships (Cornelius \& Resseguie, 2007; Siegel, 2013). Some therapeutic group models have been developed (Bunston, 2017; Bunston, Pavlidis, \& Cartwright, 2016), some focusing on processing the violence itself (Glodich \& Allen, 1998; Johnston, Roseby, \& Kuehnle, 2018; Peled \& Davis, 1995; Tjersland, 2012). A small number of documented programmes offer a strengths based approach, but these are generally not reported in peer reviewed literature (e.g. see the report provided by Campo et al, 2014, for a review of these). However, many group based interventions draw 
on a deficit model, addressing factors like difficulties with emotional regulation (Lacasa et al., 2016), disrupted attachments and trauma (Bunston, Pavlidis \& Cartwright, 2016) , behavioural and social problems. This reiterates a common representation of children and young people from domestic abuse literature, as passive and damaged (Callaghan, 2015; Katz, 2015; Overlien, 2010; Mullender et al, 2003). These interventions tend to focus on the negative impact of DVA, on dysfunctional behaviours and social skills to be removed, or irreparable damage to be contained. Whilst these kinds of interventions offer important support for YP, the focus on reparative work can overlook the strengths that YP can embody, or the strategies YP have themselves built up to cope with DVA and its aftermath (Callaghan, Alexander \& Fellin, 2016a; Callaghan et al., 2016, 2017a).

The evidence base on supporting resilience in YP who experience DVA tends to frame resilience in quite individualist terms, as typical development despite adversity (Masten, Cutuli, Herbers, \& Reed, 2009; Peterson \& Yates, 2013). In contrast, our work focuses on resilience as a multifaceted process that YP navigate in an active and engaged way in a social and relational context (Zahradnik et al., 2009; Ungar, 2011). We suggest YP's resilience is constituted through their capacity for agency and their ability to construct a resilient sense of self in relation to the violent, coercive and controlling dynamics of their family life.

This article describes the rationale and the main features of Mpower (Fellin et al., 2015), a manualised group therapeutic intervention with YP who have experienced DVA. The intervention was developed as part of an action research project (Understanding Agency and Resistance Strategies, UNARS). We interviewed 107 YP across four countries (Greece, Italy, Spain and the UK) exploring their experiences of coping with DVA. (Callaghan \& Alexander, 2015; Callaghan, Alexander \& Fellin, 2016a; Callaghan et al., 2016b; Callaghan et al., 2017). In these interviews, we learned that YP maintain a sense of agency, resilience and resistance in a range of ways: through caring relationships (Callaghan, Alexander, Sixsmith, et al., 2016); through their use of space and their material environment (Callaghan, Alexander \& Fellin, 2016a); through their expression and management of complex emotion (Callaghan et al., 2017a); and through their management of what and how they disclose their experiences (Callaghan et al., 2017b). We embedded this learning in an intervention, 
the therapeutic programme "MPOWER". It was piloted in the UK and then implemented with 60 YP across Italy, Greece, Spain and the UK.

\section{Rationale and Key Principles}

The intervention focuses on supporting YP by enhancing the strengths they build when they live with violence. Our aim was to understand YP coping, and enhance their sense of agency, mastery and empowerment (Singer, 2002; Streeck-Fischer \& van der Kolk, 2000). For this reason, the focus of the intervention is not on the violence itself, but on its effects as experienced in everyday life, its relational implications, and YP's abilities and strategies of caring and coping.

The intervention described in this article was the product of a two-phase action research project. (The project was approved by the University of Northampton Social Sciences ethics board, as detailed in the project report, Callaghan \& Alexander, 2015). The first phase involved interviews with 107 children and young people, focused on their accounts of how they coped with DVA and its aftermath (Callaghan \& Alexander, 2015). These were analysed using interpretive interactionism (Denzin, 2001) and the emergent themes from this analysis informed the development of the intervention. In these interviews, YP described how they retained a sense of agency and resistance in highly controlling and violent contexts; this was achieved through ways of being and relating rooted in their everyday contexts (their relationships, home and play spaces) (Callaghan, 2017). In other words, the experience of violence and the experience of resistance to violence were located in the material spaces and relational exchanges that characterised their worlds. Their coping strategies echoed the complexity and locatedness of their experiences of DVA. For example, children 
constructed dens and hideaways for themselves, and retained a sense of connection to friends and important family members.

\section{Principle 1: Making sense of violence and coping}

To enable a focus on recognizing and enhancing existing coping and resiliencies, we moved away from a symptom driven approach. Instead our focus was on understanding the meaning of YP's responses to violence. We used techniques (described more fully in the section "Intervention Structure") that enabled us and the YP to understand what they did, thought and felt, to understand the meaning of that response in its social, relational and spatial context.

\section{Principle 2: Violence happens in a physical and relational world}

Violence is a socially and materially located interpersonal process - the experience of violence is embedded in family relationships, socially located understandings of family and of violence, and the material spaces of home and not-home, of belongings and losses, of public and private (Callaghan et al, 2016b, 2017a, b). For this reason, responses to violence should always be located and understood within multiple contextual levels (Vetere \& Cooper, 2005, 2006). Our creative, systemic and narrative approaches enabled us to focus on relational, contextual and embodied experiences.

The narrative and systemic approach was sensitive to interpersonal relationships and to the social, material and political systems within which young people lived their lives and dealt with their familial experiences of violence (Vetere \& Cooper, 2017). The integration of creative methods within this narrative systemic framework supported young people in articulating difficult to express experiences like emotions, embodied experience and the 
relational-material context of home (Perry, 2014; Van Der Kolk, 2014). We used both established and novel group therapeutic techniques to help YP express their experience of living with violence, to identify, value and share how they managed to cope, and to enhance their coping.

Principle 3: Coping, resistance and resilience as creative experiences In their interviews, YP said creativity was something that helped them to cope and retain a sense of resistance and resilience; they valued music, play, drawing and other forms of creative expression (Callaghan \& Alexander, 2015; Callaghan et al., 2016; Callaghan, Alexander, Mavrou, et al., 2016). These became key elements of the intervention, enabling it to be both child-friendly and child-led (Callaghan \& Alexander, 2015). We prioritized techniques (described in greater detail in the section 'Intervention Structure') that enhanced creativity, embodiment and use of space. In other words, we used creative methods like dance, music, drawing, storytelling and drama, that enabled young people to explore emotions and relationships as embodied experiences, and that helped them work through their experiences in ways that were not restricted to words.

This focus on creativity and physical experience helped us to develop and elaborate the issues considered under Principle 2. We used creative, and often non-verbal, activities to support YP to develop an understanding of their own lived experiences of relationships, conflict and resolution of conflict. This was important in helping YP to understand how their relationships had been impacted by violence, coercion and power, and how they had adapted their sense of self as relational being to live with that experience. This approach 
helped to engage YP in a shared process, by blending verbal with non-verbal communication (See Callaghan et al, 2018 for the analysis of young people's feedback on the intervention).

Principle 4: Building on strengths: non-pathologising approach

Facilitators took a non-pathologising approach, focusing on YP's resources, skills and capacities, rather than on what was 'wrong' with them (Dutton, 2012). Yuen (2009, p. 7) describes this as "discovering details of the responses to the trauma" rather than focusing on the detail of the trauma itself. This approach enabled YP to talk about themselves and their experiences in varying ways, potentially finding ways to resist dominant constructions of themselves as 'victims', wounded, damaged, or stuck in cycles of repetition. This space therefore created a potential space in which YP could reposition their sense of self, relationships and family systems. YP reported that this resource-focus, together with the creative methods enabled them to draw, enact and engage with things that had previously been difficult to articulate. Using non-verbal and creative techniques renders expressible the silenced or difficult to articulate narratives, memories and questions that YP might otherwise find difficult to tell (Einarsdottir, Dockett, \& Perry, 2009; Perry, 2014). The approach allowed YP to acknowledge, and sometimes renegotiate complex family relations (for instance, ambivalent attachments to either parent, or a sense of divided loyalties in families) (Callaghan, Fellin, \& Alexander, 2016; Greco, 2006; Vetere \& Cooper, 2017).

The group based approach provided an open, consistent and safe place to experience, share, express and regulate emotions, strategies, skills and behaviours, as well as to create and experiment new bonds, roles and relations within clear boundaries and rules. It is well documented that group therapy offers a potentially less stigmatizating, pathologising and 
isolating context for young people from complex families, enabling potential empowerment and 'normalisation' through shared experience (Yalom \& Leszcz, 2005; Westergaard, 2009). By bringing similar YP together in a group encounter, we open up the potential to overcome isolation, share experience, and build a sense of belonging, solidarity and identification with the group (Sigurdardottir, Halldorsdottir, Bender, \& Agnarsdottir, 2016). This can challenge the sense of 'difference' and interiorized stigma so common among YP who experience DVA (Buckley, Holt \& Whelan, 2007; Stanley, Miller \& Richardson Foster, 2012). The sense of a shared experience can also foster a less defensive and more curious attitude in YP, by building greater understanding and empathy for the thoughts and emotions of self and others in relation to experiences of DVA. The group format also enables a sense of communal problem solving (Bloom, 1994; Falicov, 2016); YP worked together to offer each other feedback, suggestions and reinforcement.

\section{Principle 5: An emotion focused approach}

The intervention focused on emotion and relationships, but did not use the techniques of emotion coaching (Katz et al, 2007) or social skills training; we did not want to 'teach' YP how to manage their feelings and relationships. Rather our focus was on helping YP to build a better understanding of how they had experienced emotions, and managed relationships in the past, and how they wanted to work with their feelings and relationships in the future. Our focus was also widened beyond a focus on mother-child interactions (Katz, 2015; McManus et al, 2013) to explore the YPs broader relational terrain. Facilitators therefore worked with participants to develop their understanding of their responses to their experiences of violence and of family relationships, exploring what worked well, how it worked, and to experiment with refining, adapting or changing those coping skills. 


\section{Recruitment and Assessment}

The intervention was piloted in the UK, and then implemented in the four partner countries. 58 YP took part in the intervention, across the 4 participating countries, 28 girls, and 30 boys. Participants ranged in age from 11-19 years, with an average age of 15.97. Drop out rates were low, with just 3 participants dropping out after one or two sessions. (One further participant disengaged after 3 sessions for personal reasons unrelated to the group.) Young people attended an average of 7.96 of the 10 sessions, suggesting a high level of engagement with the programme. Table 1 provides fuller detail of the demographics and attendance patterns of participants. (INSERT TABLE 1 ABOUT HERE.)

Referrals to the programme were drawn primarily from the child protection services and refuge workers, with a small number coming from psychology services (3), lawyers (2) and teachers (3). YP were all in a safe place at the time of the intervention, with most living either in refuge, or in a safe home with their mother (although it was not an inclusion criteria, all YP who participated came from families where a father or step father was the main perpetrator). According to the mothers and referrers, each YP had witnessed several episodes of violence at home and could benefit from group work. Most YP had shown symptoms of psychological distress, but were not receiving mental health support. Many of the YP had previously been diagnosed with problems like dyslexia, ADHD, and conduct disorders. As noted in other literature on child survivors of DVA (Go, Kong, \& Kim, 2018; Lepistö, Luukkaala, \& Paavilainen, 2011) many of the YP were involved in bullying and/or were being bullied.

An assessment and induction interview was held with each YP and mother before the group started. YP were admitted to the group if they were considered to be in a safe situation, ready and motivated to attend the group. Two groups offered in each country, based on age and maturity levels. Motivation was an important factor in the assessment because we were committed to a non-coercive approach to working with young people. It was made clear to YP who were unsure about participation that they could join the group and see how they felt about proceeding after the first session, enabling those who were unsure to have a 
taster before settling into the group. However, the assessors did ensure that YP were present because they wanted to be, and not because they had been 'sent' by a parent or another professional.

At the assessment interview, YP were told that all group participants had been invited because they had experienced violence in their home. It was also made clear that the violence itself was not the main focus of the group, and that YP did not have to speak about the violence, unless they wanted to. Basic group rules and structure, safeguarding procedures and limits to confidentiality (in the case of a disclosure with child protection implications) were carefully explained to YP and carers at assessment interview, and informed consent was secured. The group facilitators were familiar with local voluntary and statutory resources for YP, and were able to refer YP into services where they deemed necessary.

\section{Intervention Structure}

The intervention was 10 sessions in total, including 8 main sessions, a 2 -week break and 2 follow-up sessions. Each group had 2 facilitators. Sessions ran for 90 minutes each, but the venue was available for at least 120 minutes, to allow time for warm-up, breaks and spillover. Each session started with warm up activities, such as light chat, and playing together while listening to music. Each YP filled in the Child Outcome Rating Scale (CORS), a session by session rating scale that enables YP to track their subjective wellbeing (Duncan et al., 2006). At the beginning of each group, therapists checked in with the YP, asking "How was your day/ week?" to get some feedback on their wellbeing and mood. Some fixed routines were introduced to settle and ground the YP. We offered YP several possible activities for each session, and they chose their own focus and activity. The session opened with planning activities for the session ahead, and closed with planning activities for the next session, including refreshments. The aims of activities overlapped from one session to another and some aims were covered in different ways across the activities; these were used flexibly, and tailored to the specific needs of each group. For instance, a single activity might be so successful and engaging that it became the sole focus of a particular session, and remaining planned activities might be postponed. Session by session rating scales were 
used at the end of each session, to provide a predictable form of closure, support reflection on process, and provide structured feedback to the group facilitators.

YP were invited to bring issues and topics that mattered to them to each group, and they understood this did not have to about violence or their immediate family. YP did not have to participate verbally; they could use art/media to communicate their feelings (e.g. draw a painting, write a poem, make a collage, to make a role-play or a video of situations) or could just listen to other people's accounts. Each activity was followed by unstructured discussion/reflection, exploring how YP experienced and understood what had happened. YP worked in the group to explore the relational function of their response to material they brought, and to activities in the group. They explored how and whether particular responses worked in the context, enabling recognition of coping strategies, and discussion of adapting or choosing alternative responses. In exploring their responses to violence and to relational challenges, YP explored the meaning of aggression, hostility or violence, and their emotional responses to it.

The sessions involved a wide variety of activities that aimed to enable young people to: 1) build safety and trust (in themselves and others); 2) explore, share and develop coping strategies; 3 ) challenge myths and self-fulfilling prophecies about DVA, and address YP's fears about intergenerational transmission; 3 ) build positive self-identity and envisage a positive potential future 5) foster caring relationships and social support; and 6) deal with endings and experiences of loss.

\section{Building safety and trust}

In the first sessions, our main focus was on getting to know each other, and building a safe and trusting space for us to work in together. To develop trust in themselves and others can be particularly challenging for YP who have experienced DVA (Callaghan, Fellin, et al., 2017; Mullender et al., 2003). They may also find articulating their experiences complex or challenging (Callaghan, Alexander, et al., 2017; Tjersland, 2012). YP who experience DVA often see disclosure as risky, and are cautious about who they trust with their stories, and how they narrate their experiences (Callaghan, Alexander, et al., 2017). We therefore 
developed a range of strategies to support YP in building trust and in finding a range of ways to articulate and express their experiences.

After a brief introduction, explaining the purpose of the group as a whole, ice-breaking and warming up activities allowed participants (including facilitators) to introduce themselves to each other and to lay foundations to develop trust and build a safe space in the group. YP were encouraged to visualize their own safest place (real or imaginary), leading to a discussion about feeling safe in the group. YP were asked to write or draw on post-its their responses to the questions: What are your biggest worries about taking part in this group? What practical things can we do to help you feel better in the group? We developed an agreement that all participants would adhere to some shared values: Confidentiality; Respect; Right to talk / not to talk in groups; and Boundaries. It was particularly important for the YP in these groups that there was respect for all forms of expression, including drawing, sculpting, movement, talking out loud, as well as silence and non-active participation. We co-constructed a ground rules poster, displayed (and amended if needed) throughout the group sessions. The ground rules included boundaries and rules about contacting other group members and facilitators. This included guidance on the safe use of social media. As part of the process, we also agreed safety plans that reflected each local context and conditions, and YPs' age and maturity.

Having a predictable, agreed structure was one way we fostered a sense of security in the group. YP were offered preparatory activities for each session, so that they knew what to expect. We also invited YP to take turns to bring a piece of music (a favourite record, an instrument to play, or to sing a song). This offered a routine, enjoyable opening or ending to each session. It also enabled discussion of the meaning and importance of music in their lives, potentially enabling further bonding and sharing. Music could be played throughout the session, facilitating a sense that the group was their space, and YP could move to the music if they wanted to.

YPs capacity for agency and control is often challenged by coercive, controlling and manipulative dynamics in families affected by DVA (Callaghan et al, 2016; Katz, 2016). In addition, some YP have reported that they can feel either overlooked or pressured into 'telling their story', and that they worry about how disclosures will be understood and used 
by others (Callaghan et al, 2016b). In our intervention, therefore, it was important to focus on restoring and enhancing YPs sense of agency and control, by foregrounding YP's right to choose if, when and how to participate in the group. Throughout the intervention, we emphasized that it was perfectly acceptable not to trust and not to share, especially early in the intervention. Pressuring participation positions YP as passive recipients of adult intervention work.

For YP affected by DVA, every group activity involved some element of risk, and trusting others was not just about confidentiality, but also how others might react to their disclosures of stigmatized or shame-filled experiences, like difficulties in the family, or experiences of bullying. We used bodily techniques derived from systemic, group and creative therapies (Papp, Scheinkman, \& Malpas, 2013; Perry, 2014; Roseby, Johnston, Gentner, \& Moore, 2005). This included familiar techniques like the trust lean, and willow in the wind, as well as more bespoke activities. In the 'trust lean', young people worked in pairs, assigning themselves the role of faller and catcher. After some instruction in safe falling and catching, the 'faller' YP would indicate they were ready to fall, and the 'catcher' would say when they were ready to catch. The faller, with hands crossed over their chest, falls backwards into the waiting arms of the catcher. This is practiced multiple times, perhaps increasing the depth of the 'fall', until both parties feel safe, and that they have fully explored the roles. They then swap over. A potentially gentler option is the 'willow in the wind', in which the entire group stands shoulder to shoulder, with their hands out in front of them palms facing towards the 'faller' who, when ready, leans into the catchers, starting with a gradual lean, before expanding their lean as trust builds. Both of these activities are followed by a debrief, exploring the feelings evoked in all parties.

In the activity 'Personal Space', YP worked with partners to explore how it felt to have someone physically close, and to establish their own sense of boundary in relation to physical closeness. This was achieved by having their partner approach them slowly, from various directions, and asking them to stop when they reached the space where closeness became uncomfortable. This space was marked with a beanbag, before the exercise was repeated from a different angle. This gives a visual mapping of each YPs use of space, their comfort with embodied experiences of closeness and their experiences of setting explicit 
boundaries in relation to their embodied selves. This activity enabled the group to experience and discuss the challenges and hindrances of trusting someone, whilst becoming aware of trust and mistrust as an embodied experience. Some participants also reported that this was their first experience of reflecting on, and respectfully and positively setting physical boundaries - clearly important for YP recovering from experiences of violence in the family.

Building trust took significantly longer than facilitators had experienced in other kinds of therapeutic group intervention not related to DVA, and some YP did not share much of their own story/personal experience at all. This may relate to the issues YP reported around trust and disclosure (Callaghan, Alexander, et al., 2017)- including concerns about maintaining family secrets, managing disclosures in relation to who they could and could not trust, and concern about the risks of disclosure. Nonetheless, these YP reported feeling safe and contained in the group (perhaps because of the lack of pressure for them to disclose) and they also indicated that hearing the experiences and strategies others shared helped them to process their own. By providing a place where we made it clear and explicit that it was possible and acceptable not to trust and not to disclose, we created a safe place where trust could be fostered.

\section{Sharing and working with coping strategies}

A key aim in this intervention was to support YP in sharing, processing and enhancing their ways of coping with DVA. In this way, we sought to facilitate YP's recognition of their own agency and mastery as they coped with their experiences of violence and coercion, shifting any positioning of them as passive victims, and celebrating their personhood and their capacity for resistance. Discussions were mediated by adult facilitators, but ideas and solutions were put forward by YP. Shared experiences created opportunities for reciprocal role-modeling, enabling participants to practice different ranges of responses and learn from each other. This sharing supported YP in expanding their toolkit of resources and coping strategies. This ongoing exchange also allowed participants to feel empowered and helpful to each other, boosting their self-esteem, and facilitating a sense of belonging, cohesion and support. In this way, YP were able to build trust and hope in themselves and others. For example, through discussion, YP did have an opportunity to reflect on and 
learning about their emotions and to understand 'normal' trauma and fear responses. In addition, bullying and other aggressive relational practices emerged organically in the group as a source of considerable concern to YP, and space was given to enable YP to work through puzzling, complex or aggressive interactions and relationships. With the exception of one all male group in Greece, the group was mixed gender, enabling space for a dialogue and curiosity about gendered experiences of violence with other YP who were not from their own family or immediate circle of friends.

This approach produced a sense of solidarity built on shared experience, challenging YP's sense of isolation and difference, and allowing them to see that they were not alone in the adversities they had faced. One strategy we used was to share anonymised interview and photovoice extracts from the "UNARS" study (See appendix 1 for an example), enabling participants to recognize (often with some surprise) that even in other countries, there were YP who had similar experiences to their own. The group constituted often the first arena in which they could identify with peers, who coped in similar ways to them, for instance through escapism or music, or self-harm and risky behaviours. They also heard stories that might echo experiences of others in their family, who had responded differently to them enabling them to empathise or understand others' positions more fully; for instance, gaining awareness that a group member reminds them of a sibling who tends to act as the troublemaker' to distract parents from their issues or, to the contrary 'becomes invisible' not to cause further concerns. The slight distance enabled by sharing someone else's photovoice enabled them to recognize that their own behaviours, emotions and reactions, especially those labelled as 'problematic' or 'pathological', were also powerful coping strategies, shared by others; for instance, difficulties in concentration, distractibility and hyperactivity are normally constructed by professionals, and hence by YP themselves, as symptoms of poor academic skills, or learning difficulties or ADHD. During group conversations it was possible to understand they could rather be an adaptive alert and hyper-vigilant reaction to a specific relational context dominated by constant fear and concerns about violence happening at home. Having identified the adaptive function of their emotions, reactions and behaviours in context, they could appreciate them rather than frame them negatively. This opened up the potential for more flexibility in their responses. Through their communal experience as YP who had survived DVA, they could equip themselves with additional and 
alternative strategies, supporting a greater sense of social and emotional efficacy and competence.

YP produced individual or shared creative work based on each key discussion - an image or object that represented the issues and solutions that had been discussed. This creative product offered further evidence of their shared achievements and skills, and left a legacy of what they had done together. Many of the YP wanted to take these objects home with them, to keep in their rooms, as a reminder of all they had lived and achieved.

\section{Challenging self-fulfilling prophecies}

A pervasive representation of YP who have survived DVA is that they suffer lifelong damage. For example, the discourse of 'intergenerational transmission' suggests that, without intervention, YP are doomed to repeat the relational patterns of their parents (Ehrensaft, Cohen, Brown, Smailes, Chen, \& Johnson, 2003; Black, Sussman \& Unger, 2010; Siegel, 2013). This was a prevailing concern for many YP in both the interviews we conducted for UNARS (see Callaghan and Alexander, 2015), and in the intervention groups. Drawing on both common sense and professional language, YP worried that surviving DVA meant they would grow up to be 'just like their mum/dad' and worried about their potential to be victims or abusers.

Several group activities focused on the theme of violence from different perspectives. As we explored together the meaning and function of violence in different relationships and contexts, we were able to also deconstruct some of these myths around the inevitability of 'inheriting' family violence. To reduce anxiety YP only had to talk about their own experiences if they chose to, and one-step-removed materials were available for them to use if they preferred.

To explore family relations and legacies, we used creative techniques, including classic systemic tools (family maps and sculpting, eco-maps)(Duhl, Kantor, \& Duhl, 1973), as well as narrative tools (e.g. the Tree of Life, Ncube, 2006). Through these tools, YP could position themselves and family members, exploring similarities and points of difference between themselves others: for example those who bottle up emotions and those who act them out 
or else express them through creative arts. These techniques also helped YP to look at the constraints and resources offered by their family and social networks, including anything positive they learnt or shared with perpetrators (e.g. passion for football, watching matches together, good memories of childhood holidays). These tools also offered the opportunity for YP to reflect on and understand the complex relational and situated contexts in which family violence occurred. This kind of reflection was often not enabled within the family itself, where the trauma of the violence may be acknowledged, but is rarely articulated or directly processed (Callaghan et al, 2016a and b, Callaghan et al, 2017).

YP were able to voice their anxiety and worries being trapped in cycles of family violence, and could work through their internalization of transmission myths. This could be very painful to articulate, and the emotions evoked were unsettling and distressing. The group offered solidarity and shared experience, as well as robust and positive in challenges to these pervasive myths. This offered powerful reassurance to group members about their own resilience and capacity to resist narratives of repetition. YP could express a sense of agency, and of potential capacity to choose a different path and to grow into a different kind of man or woman from those in their family.

\section{Building a positive self-identity and envisaging a positive potential future}

A related component of the intervention focused on deconstructing YPs' negative identifications, opening up space for more positive self-identities to be expressed and confirmed within the group context. Our sense of self is constituted in family and communal relations, and the experience of DVA can leave YP feeling marginalized and rejected. This can impact negatively on YP's sense of self. Internalised stigma, a sense of feeling different and marginalized, can have a profound negative impact on the lifelong wellbeing of YP (Vetere and Cooper, 2016). The solidarity experienced in group work can reduce stigma and marginalization, challenging the sense of difference and damage, and offering a communal foundation for the construction of a positive potential sense of self. Participation in communal problem solving also bolsters a sense of confidence and mastery. This process helps YP reposition their sense of self as someone who has survived adversity, and found ways to cope. This enables YP to feel a sense of positive personal power and undermines the dominant positioning of them as vulnerable, damaged victims. Through the experience 
of feeling connected rather than feeling isolated, different, silenced and insecure, YP can construct a sense of hope and a more proactive stance towards their future life and relationships.

This crucial objective was also targeted directly in tailored activities that were intended to address issues of identity. Narrative tools like Pride Collages (Fellin, Callaghan and Alexander, 2015) and the Tree of Life (Ncube, 2006) were powerful ways to highlight YPs' gifts, skills and resources. In the Pride Collage, young people built individual and then communal accounts of their personal and group strengths using collage techniques. The Tree of Life is a more personal account of connection to family and heritage, in which young people represent themselves as a tree with roots (family, community), branches (aspirations), leaves (significant people) and fruits (their gifts and skills). Some structured but playful conversations encouraged YP to think in a future oriented and positive way (E.g. "Imagine yourself in 20 years time. Looking back on the time we have shared together in this group, what has it given you that will be important to your future self? What do you think you've given to others in this group?"; Thinking about ideal vs realistic 'dream life' and how to achieve it). These activities were consolidated in the closing sessions, using narrative therapy tools (including certificates, celebrations, and public exhibition of YPs' artwork, see Vetere \& Cooper, 2017; White \& Morgan, 2006) to consolidate YP's skills, achievements and success.

\section{Fostering caring relationships and social support}

Building positive relationships within the group was at the heart of all aims and activities of the group intervention. We assumed positive relationships within the group would create the potential for generalization beyond the group, as YP experienced themselves as potentially positive relational beings (Bunston, Pavlidis \& Cartwright, 2016; Bunston, 2017). The group offered an intersubjective space in which relational challenges could be articulated and processed. In our group interactions, intersubjectivity was defined as a context of "interacting subjectivities, reciprocal mutual influence, colliding organizing principles, conjunctions and disjunctions, attunements and malattunements" within which our sense of self (YP and therapist) is constituted (see Stolerow \& Attwood, 1992). In other words, intersubjectivity is the relational space within which our sense of self is constructed. 
The relational issues YP chose to bring included family issues, but they also brought relational issues from wider social networks (friends, romantic partners, school staff, social workers, sport teams, colleagues). Importantly, the group also offered a safe arena in which they could share and revisit their often ambivalent relationship with the perpetrator (a father or step-father), their mother and siblings and other significant people. Through shared memories and narratives, YP were able to decenter from the immediate focus on self, and put themselves in the shoes of the relational other, experiencing the potential for empathy with their family members. This was a potentially powerful aspect of the intervention, particularly for YP who had difficulty talking about their relationship with their abusive (step)parent. This enabled a disruption of polarized thinking about the (step)father as entirely bad, supporting a realistic appraisal of the perpetrator as a whole person, with his own strengths and challenges (Callaghan et al, 2018). This functioned to support YP in demystifying the male abuser, in some cases reducing the image of him as all-powerful and terrifying, and in others, enabling a recognition and integration of some of the more positive elements of their relationship with him. This process did require very careful attention to safety concerns, to avoid the risk of any idealisation of the perpetrating parent. YP were also able to make a more realistic appraisal of their relationship with their mother.

The group process itself offered useful opportunities to consider conflict and responses to conflict. Disagreements within the group were rare, but when they did arise, over activities, group dynamics or relational ruptures, these were harnessed and used fruitfully, to explore peaceful and respectful negotiation and to support the development of conflict resolution skills (Bunston, 2017).

YP were progressively more able to voice their concerns and worries about issues within the group, and to state when another member's behavior was troubling them. The group dimension of reciprocal respect, acceptance and recognition was a necessary condition that made it possible for YP to be open, often for the first time, in an authentic and vulnerable way about intimacy, emotions and relational issues. This was stablished through the trust building that characterised the first few weeks of the group, as well as the mutual exchanges that developed across the group process. Early in the group, many participants reported social stigma, isolation, bullying and a lack of close friends or social support. 
Group cohesion, a central therapeutic element in any group work (Yalom \& Leszcz, 2005) took on a particular therapeutic value with these YP, whose relational history has been so fraught and so complex (Bunston, 2017). Feeling integrated and belonging to a group was a crucial healing experience. Participants built a strong relational bond as a group and used it to experiment with new relational ways of being, which they reported they could transfer to the world beyond the group. They also built close relationships with each other in subgroups, especially during breaks and unstructured activities. However, the deep connection among participants, as well as with facilitators, did make approaching the end of the group very challenging.

\section{Deal with endings and loss}

Given how important relationships within the group had become, it was inevitable that ending the group would be a sensitive issue for many group participants, including facilitators. We maintained a focus on endings and closure across the group. For instance, on the small number of occasions when individual participants dropped out of the group, as a result of changed circumstances, or because YP felt this was not the right time for them to engage, we used this experience as an opportunity to discuss different ways of coping, and ways of managing loss. For the YP who wanted to dropout, this was discussed either face to face where possible, or by telephone where not, with the YP and / or their carer. For the YP who remained in the group, space was created to discuss how they felt about the person leaving.

The last few sessions were devoted to preparing the group for the end by celebrating its achievement and its legacy. Feelings of sadness, abandonment and disillusion were common and all YP expressed a wish that the intervention were longer. The group focused on creative activities to build something that represented their collective journey, and that left a lasting imprint of their communal experience. Participants created a group collage. Each member was invited to add material or draw on a large piece of paper laid out on the floor, and in this way, they created a group image. At each step in the construction of the collage, each participant would say something about how they saw the image evolving, and what they "saw" as the final image or theme. Participants also discussed how it felt to have 
their contributions altered or added to by the other members. In addition, participants worked together to create memory boxes full of messages of acknowledgement and appreciation for each other and for the facilitators. Group participants also made contributions to a public exhibition, that drew together the creative products of the whole UNARS project. This exhibition was attended by local policy makers and other community members, and offered YP the opportunity to have their voice heard in a wider forum. Many group participants also volunteered to take part in a post-intervention interview, as part of the evaluation of the intervention, so that their experience could inform research, policy and practice, and help other people in the same situation, enhancing the sense of a lasting legacy and meaning from their experience.

\section{Discussion and conclusions}

This paper provided an overview of a group-based intervention for YP who have lived with DVA, developed and piloted across four European countries. Whilst much academic and professional literature has positioned these YP as only passive 'victims' and 'witnesses', 'damaged' by the DVA they live with (see Callaghan 2015; Katz, 2015; Øverlien, 2010; Mullender et al, 2003), our intervention focused on acknowledging the things they did to cope with and resist the violence and coercion in their families, and enhancing those existing resiliencies and strategies of resistance. In both the underpinning "UNARS" research (Callaghan \& Alexander, 2015) and the intervention itself, YP demonstrated how agentic and skillful they could be in coping with the fallout of family violence. This stands in stark contrast with much published work in this area that suggests that this group have more 'concrete' or dysfunctional styles of relating and reduced emotional competence (Katz, Hessler, \& Annest, 2007; Katz \& Windecker-Nelson, 2006) and limited potential for full recovery (see Bunston, 2016 and $\varnothing$ verlien \& Hydén, 2009 for critical commentary on the assumption children and young people have limited capacity for recovery). An overreliance on normative constructions of childhood and pathologising discourses around trauma tends to obscure and underestimate the complex and powerful individual and relational strategies and competences YP unavoidably develop in order to cope with adversities and to manage the physical and emotional impact of family violence. 
While DVA literature often suggests that YP who have experienced violence are less able to manage emotional situations, or to understand the emotional needs of other people and respond accordingly (Katz et al., 2007; Katz \& Windecker-Nelson, 2006), our experience in carrying out this intervention shows that it is important and effective to offer a safe place to identify, discuss and value their own and others' emotional responses and coping strategies. This builds on the intervention work of other trauma informed and systemic practitioners, who have stressed the importance of attending to YPs' capacity to express their relational experiences and to work with their emotions in complex and productive ways (e.g. Bunston, 2017; Bunston et al, 2016; Vetere \& Cooper, 2017). Offering a group space that values YPs capacity and resources helps to empower YP and enhances their sense of agency, reciprocal sharing and acknowledgement. Although the programme did not focus on the getting YP to talk specifically about their experience of violence, many YP did share experiences related to it, and to the relational dynamics that were associated with the violence (e.g. experiences related to coercive control). YP appeared to feel progressively safer in the group, able to reciprocally accept and give support. This exchange of disclosure and support seemed one of the most empowering factors of the group experience.

We have identified several key components of group work that enabled YP to work productively with their histories of violence, to recognize their own strengths, and to challenge their own perceptions that they were trapped in dysfunctional styles of relating. A safe space was enabled by the construction of clear boundaries and a reciprocal climate of respect. Creative and embodied activities offered alternatives to verbal disclosure, and YP were clear that they could choose when and how to participate or not. All shared experiences were respected and validated, and YP were supported in acknowledging the complexity and ambivalence of their relational and emotional experience. There was an explicit shared value placed on fostering caring relationships within the group, while the blend of structured and unstructured activities seemed to further strengthen the feelings of mutual trust and belonging. This environment enabled exploration of YPs' strategies for coping with and resisting violence and its aftermath. Further, YP clearly articulated the importance of having space to work through the complexity of their relationships with the perpetrating parent, and to have an opportunity to talk through their relationships with others. There was a recognition that these experiences can be difficult to articulate, and 
that the language to describe family violence is not always readily available (Callaghan et al, 2016b). The cumulative effect of these therapeutic principles contributed to the construction of a more positive, competent and agentic self-identity and a capacity to envisage a positive potential future, freer from violence and with the possibility of healthy relationships. To support YP in retaining the gains of the group, a strong emphasis was placed on managing the ending of the group, and ensuring that the group had a lasting and visible legacy.

Although the group was very positively viewed by participants, parents and the DVA organisation in which the group was run, there were difficulties in implementation that should be acknowledged. A particular challenge in working with YP affected by DVA related to adult gatekeeping practices. Although there is clear evidence of significant need for such groups (CAADA, 2014) referral patterns were erratic, and many professionals expressed concerns about YP being 'too vulnerable' to do the work. This perception of YP affected by violence as extremely fragile and too easily 'triggered' can overstate the vulnerability of YP, in a manner that can potentially block them from articulating their own experiences, or having a say in whether they access support or not (Callaghan \& Alexander, 2015; Eriksson \& Nasman, 2012). In offering this kind of group work, it is therefore important to devote considerable time to recruitment, and to working with potential referrers to support appropriate referral, challenge unnecessary gatekeeping, and undermine the use of myths about DVA in professional contexts.

Attending a group labelled as DVA can lead to further stigmatisation and uneasiness in YP, so privacy should be carefully preserved, especially if interacting with professionals who support YP in other contexts (such as the school). It is important to recognize when preparing group interventions for YP affected by DVA that social anxiety and embarrassment might be stronger than in individual and family therapy, especially in the early stages of the intervention. This seemed to be particularly the case for younger boys in the groups, who could be quite disruptive until the group dynamic settled.

Therapists adapted their delivery and varied the activities used with different groups of YP, to meet the needs of YP with different levels of maturity and interests. For practical reasons, 
some partners did have to mix older and younger individuals in the groups, and generally this was not seen as ideal by therapists or YP. When assessing YP for participation, it is important to bear in mind their level of social and emotional maturity as well as their chronological age in order to ensure that they are well-matched with other group participants. Disruptive group dynamics and roles are typical of group interventions, and younger participants in particular may act-out discomfort in ways that can interfere in the group process. By enabling these to be respectfully aired we learned the value of offering space to discuss and resolve tensions and conflicts in constructive ways as central to recovery from violence, conflict and control in the family. YP affected by DVA can be more sensitive to group pressures and conformity issues, and for this reason it is particularly important to explore issues relating to disclosure, choice and confidentiality to ensure YP are protected in the group.

The MPower programme was adapted to local contexts in four different European countries, but specific cultural adaptations may be required if working with more diverse populations. In Greece and in Spain, the specific needs of refugee families posed particular issues for the groups, and required more subtle attention to cultural diversity and migration stress within the groups. In each context, UNARS staff worked closely with local stakeholders to adapt their work to the needs to specific and diverse populations. However, cultural assumptions around family life, gender and the public/private divide, as well as the impact of migration stress, socioeconomic conditions, poverty and relative deprivation are all issues that need to be more thoroughly addressed in future research on therapeutic work with children and young people affected by domestic abuse.

Due to funding constraints, the pilot of MPower was run without a parallel support group for parents. The availability of more holistic support was a clear limitation of this programme (see Bunston et al, 2015; Bunston, 2017; Katz, 2016; Stanley et al, 2011), and has been factored into our planning for subsequent deliveries of the intervention. We were also acutely aware of delivering this intervention in times of significant socioeconomic uncertainty. DVA services in particular have borne the brunt of 'austerity' or 'financial crisis' economics, and our work is set against a context in which support for families is in constriction. This has implications for the future provision of work, particularly as many 
DVA groups focus increasingly on their 'main' provision for adult female victims. The importance of supporting the development of positive services for young victims of DVA and coercive control may require a widening of the focus of DVA legislation and policy to better recognize its impact on YP (See also Katz, 2016; Callaghan et al, 2016; Houghton, 2017).

Although the direct YP voices are absent from this paper, their reflections on their participation in these groups are presented in another paper (Callaghan et al, 2018), as are the results from routine outcomes measures (ROMs) that were used to track therapeutic change and group cohesion at the beginning and the end of each. The overall positive feedback of YP was balanced against a sense of insufficient time, and a strongly expressed view in all four countries that 10 sessions were not sufficient for the work that YP wished to do as part of the intervention (see also Houghton, 2017; Bunston et al, 2017). The toolkit we developed for the programme (Fellin et al., 2015) is sufficiently flexible to extend the duration of the programme beyond 10 sessions when practically and financially viable. Future iterations of the MPOWER programme will run over a longer period, where funding and commissioning practices enable this. As Bunston et al (2017) note, it is important, as far as possible, not to rush this work.

With its emphasis on recognizing and enhancing the strengths of $Y P$, and on articulating and sharing their lived experience of DVA and its aftermath, our intervention offers an alternative to other groups offered to YP in these circumstances, and adds to a relatively small literature on therapeutic groups in this arena. We focused on developing an ongoing process of reciprocal modeling also to support YP in building a sense of relational competence, a more positive sense of self, and an enhanced sense of agency and confidence. This approach has important implications for how researchers and practitioners make sense of YP's experiences, and of their capacity for change. We argue that this intervention offers a possible route into a more respectful, embodied and resource-focused approach to help YP who experience DVA. By focusing on the meanings and functions of YPs' lived experiences, including the most problematic ones, we took seriously YPs' capacity as meaning making and reflexive beings, rather than seeing them as merely reacting to and being socialized by their family context. 


\section{References}

Alexander, J. H. et al. (2016) Children's Corporeal Agency and Use of Space in Situations of Domestic Violence. In Horton, J. and Evans, B. (Eds.), Geographies of Children and Young People. Play, Recreation, Health and Well Being. Singapore: Springer.

Baldry, A. C. (2003). Bullying in schools and exposure to domestic violence. Child Abuse \& Neglect, 27(7), pp. 713-732. doi:10.1016/S0145-2134(03)00114-5

Black, D. S., Sussman, S. \& Unger, J. B. (2010). A further look at the intergenerational transmission of violence: witnessing interparental violence in emerging adulthood. Journal of interpersonal violence, 25(6), pp. 1022-42. doi: 10.1177/0886260509340539.

Bloom, S. L. (1994). The Sanctuary Model. In Williams, M. B. and Sommer, J. F. (Eds.), Handbook of posttraumatic therapy: A practical guide to intervention, treatment, and research. Westport: Greenwood, pp. 62-68. Available at: http://www.sanctuaryweb.com/TheSanctuaryModel.aspx.

Buckley, H., Holt, S. \& Whelan, S. (2007). Listen to me! Children's experiences of domestic violence, Child Abuse Review, 16(5), pp. 296-310.

Bunston, W. (2017). Children exposed to family violence. In Haen, C. and Aronson, S. (Eds.), The handbook of child and adolescent group therapy. New York: Routledge, pp. 404-413.

Bunston, W., Franich-Ray, C., \& Tatlow, S. (2017). A diagnosis of denial: How mental health classification systems have struggled to recognise family violence as a serious risk factor in the development of mental health issues for infants, children, adolescents and adults. Brain Sciences, 7(133). doi:10.3390/brainsci7100133

Bunston, W., Pavlidis, T. and Cartwright, P. (2016) Children, Family Violence and Group Work: Some Do's and Don'ts in Running Therapeutic Groups with Children Affected by Family Violence. Journal of Family Violence, 31(1), pp. 85-94. doi: 10.1007/s10896-015-9739-1.

Bunston, W. (2016). Children, Family Violence and Group Work: Some Do's and Don'ts in Running Therapeutic Groups with Children Affected by Family Violence. Journal of Family Violence, 31, pp. 85-94.

CAADA (2014) In plain sight: The evidence from children domestic abuse. Cardiff: CAADA.

Callaghan, J. (2015). Mothers and children? Representations of mothers in research on children's outcomes in domestic violence. Psychology of Women Section Review, 17, pp. 13-20. 1466-3724.

Callaghan, J. E. M. et al. (2016a). Beyond "witnessing": Children's Experiences of Coercive Control in Domestic Violence and Abuse, Journal of Interpersonal Violence. Online Ahead of Publication. https://doi.org/10.1177/0886260515618946

Callaghan, J. E. M. et al. (2016b). Children's experiences of domestic violence and abuse: siblings' accounts of relational coping, Journal of clinical child psychology and psychiatry, 21(4), pp. 649-668.

Callaghan, J. E. M. et al. (2017a). Children and Domestic Violence: Emotional Competencies in Embodied and Relational Contexts, Psychology of Violence, 7(3), pp. 333-342. doi: 10.1037/vio0000108. 
Callaghan, J. E. M. et al. (2017b). Practices of Telling, and Not Telling: The Management of Disclosure in Children's Accounts of Domestic Violence, Journal of Child and Family Studies, 26(12), pp. 3370-3387. doi: 10.1007/s10826-017-0832-3.

Callaghan, J. E. M. \& Alexander, J. H. (2015). Understanding Agency and Resistance Strategies: Children's Experiences of Domestic Violence. Northampton. Available at: www.unars.co.uk.

Callaghan, J. E. M., Alexander, J. H. \& Fellin, L. C. (2016a). Children's embodied experiences of living with domestic violence: "I'd go into my panic, and shake, really bad", Subjectivity, 9(4), pp. 399-419. doi: 10.1057/s41286-016-0011-9.

Callaghan, J. E. M., Fellin, L. C. and Alexander, J. H. (2017a) Beyond Vulnerability: Working with children who have experienced domestic violence. In L. O'Dell, C. Brownlow, and H. Bertilsdotter-Rosqvist. (2016). Different Childhoods. London.

Callaghan, J. E. M., Fellin, L. C. and Warner-Gale, F. (2017b). A critical analysis of Child and Adolescent Mental Health Services policy in England, Clinical Child Psychology and Psychiatry, 22(1), pp. 109-127. doi: $10.1177 / 1359104516640318$.

Campo, M., Kaspiew, R., Moore, S., \& Tayton, S. (2014). Children Affected by Domestic and Family Violence: A review of domestic and family violence prevention, early intervention and response services. Retrieved from:

https://www.women.nsw.gov.au/_data/assets/file/0014/300623/PDF6 Final_Report_Children_affecte d.pdf

Carrell, S. E. \& Hoekstra, M. L. (2010). Externalities in the Classroom: How Children Exposed to Violence Affect Everyone's Kids, American Economic Journal: Applied Economics, 2(1), pp. 211-228.

Cornelius, T. L. \& Resseguie, N. (2007). Primary and secondary prevention programs for dating violence: A review of the literature, Aggression and Violent Behavior, 12(3), pp. 364-375. doi: 10.1016/j.avb.2006.09.006.

Duncan, B.L., Sparks, J.A., Miller, S.D., \& Bohanske, R.T. (2006). Giving Youth a Voice: A Preliminary Study of the Reliability and Validity of a Brief Outcome Measure for Children, Adolescents, and Caretakers. Journal of Brief Therapy, 5(2), pp71-88.

Ehrensaft, M. K. et al. (2003). Intergenerational transmission of partner violence: A 20-year prospective study, Journal of Consulting and Clinical Psychology, 71(4), pp. 741-753. doi: 10.1037/0022-006X.71.4.741.

Falicov, C. J. (2016). The multiculturalism and diversity of families, in Sexton, T. and Lebow, J. (eds) Handbook of Family Therapy. New York and London: Routledge, pp. 66-86.

Fellin, L.C., Callaghan, J.E.M. \& Alexander, J.H. (2015). Understanding agency and resistance strategies (UNARS) Intervention Manual and Toolkit (MPOWER Programme). Northampton, UK: University of Northampton.

Graham-Bermann, S. A. \& Hughes, H. M. (2003). Intervention for Children Exposed to Interparental Violence (IPV): Assessment of Needs and Research Priorities, Clinical Child and Family Psychology Review 6(3), pp. 189-204.

Graham-Bermann, S. A., Lynch, S., Banyard, V., DeVoe, E. R., \& Halabu, H. (2007). Community-based intervention for children exposed to intimate partner violence: an efficacy trial. Journal of Consulting and Clinical Psychology, 75(2), 199-209. 
Gewirtz, A. H., \& Edleson, J. L. (2007). Young Children's Exposure to Intimate Partner Violence: Towards a Developmental Risk and Resilience Framework for Research and Intervention. Journal of Family Violence, 22(3), 151-163. doi:10.1007/s10896-007-9065-3

Holt, S., Buckley, H., \& Whelan, S. (2008). The impact of exposure to domestic violence on children and young people: a review of the literature. Child Abuse \& Neglect, 32(8), pp. 797-810. doi:10.1016/j.chiabu.2008.02.004

Houghton, C. (2015). Young People's Perspectives on Participatory Ethics: Agency, Power and Impact in Domestic Abuse Research and Policy-Making. Child Abuse Review, 24, pp. 235-248. doi: 10.1002/car.2407.

Howarth, E. Moore, T.M., Welton, N.J. et al. (2016). Improving Outcomes for children exposed to domestic ViolencE (IMPROVE): an evidence synthesis, Public Health Research, 4(10), pp. 1-342. doi: 10.3310/phr04100.

Howell, K. H. (2011). Resilience and psychopathology in children exposed to family violence. Aggression and Violent Behavior, 16(6), pp. 562-569. doi:10.1016/j.avb.2011.09.001

Humphreys, C., \& Bradbury-Jones, C. (2015). Domestic abuse and safeguarding children: Focus, response and intervention. Child Abuse Review, 24(4), pp. 231-234.

Katz, E. (2015). Domestic Violence, Children's Agency and Mother-Child Relationships: Towards a More Advanced Model. Children \& Society, 29(1), 69-79. doi:10.1111/chso.12023

Katz, E. (2016). Beyond the Physical Incident Model : How Children Living with Domestic Violence are Harmed By and Resist Regimes of Coercive Control, Child Abuse Review, 25, pp. 46-59. doi: 10.1002/car.

Lacasa, F. et al. (2016). Emotion Regulation and Interpersonal Group Therapy for Children and Adolescents Witnessing Domestic Violence: A Preliminary Uncontrolled Trial, Journal of Child \& Adolescent Trauma. doi: 10.1007/s40653-016-0126-8.

Lepistö, S., Luukkaala, T., \& Paavilainen, E. (2011). Witnessing and experiencing domestic violence: a descriptive study of adolescents. Scandinavian Journal of Caring Sciences, 25(1), 70-80. doi:10.1111/j.1471-6712.2010.00792.x

Masten, A. S. et al. (2009). Resilience in development. In S.J. Lopez and C.R. Snyder, (2009). Oxford handbook of positive psychology. New York: Oxford University Press, pp. 117-131.

McManus, E., Belton, E., Barnard, M., Cotmore, R., \& Taylor, J. (2013). Recovering from Domestic Abuse, Strengthening the Mother-Child Relationship: Mothers' and Children's Perspectives of a New Intervention. Child Care in Practice, 19(3), 291-310. doi:10.1080/13575279.2013.785933

Meltzer, H., Doos, L., Vostanis, P., Ford, T., \& Goodman, R. (2009). The mental health of children who witness domestic violence. Child \& Family Social Work, 14(4), 491-501. doi:10.1111/j.1365-2206.2009.00633.x

Mullender, A., Hague, G., Imam, U. F., Kelly, L., Malos, E., \& Regan, L. (2003). Children's Perspectives on Domestic Violence. London: Sage.

Ncube, N. (2006). The Tree of Life. Using Narrative ideas in Work with Vulnerable Children in South Africa. International Journal of Narrative Therapy and Community Work, 1, pp. 3-16.

$\emptyset$ verlien, C., \& Hydén, M. (2009). Children's actions when experiencing domestic violence. Childhood, 16(4), 479-496. 
$\emptyset$ verlien, C. (2010). Children Exposed to Domestic Violence: Conclusions from the literature and challenges ahead. Journal of Social Work, 10(1), pp.80-97.

Perry, B. D. (2014). Creative interventions with traumatized children. Surrey: Guilford Publications.

Peterson, S. M. and Yates, T. M. (2013). Early Childhood Relationships and the Roots of Resilience. In Encyclopedia on Early Childhood Development. Montreal: CEECD, pp. 1-6.

Radford L, Corral S, Bradley C, et al. (2013). The prevalence and impact of child maltreatment and other types of victimization in the UK: findings from a population survey of caregivers, children and young people and young adults. Child Abuse Neglect, 37:801-13.

Siegel, J. P. (2013). Breaking the links in intergenerational violence: an emotional regulation perspective. Family process, 52(2), pp. 163-78. doi: 10.1111/famp.12023.

Sigurdardottir, S. et al. (2016). Personal resurrection: Female childhood sexual abuse survivors' experience of the Wellness-Program, Scandinavian Journal of Caring Sciences, 30(1), pp. 175-186. doi: $10.1111 /$ scs.12238.

Smith, E. (2016). Domestic Abuse, Recovering Together. Leicester.

Stanley, N., Ellis, J., \& Bell, J. (2011). Delivering preventive programmes in schools: Identifying gender issues. In C. Barter \& D. Berridge (Eds.), Children Behaving Badly: Peer Violence Between Children and Young People (Vol. 31, pp. 217-230). UK: Wiley.

Stanley, N., Miller, P. and Richardson Foster, H. (2012). Engaging with children's and parents' perspectives on domestic violence, Child \& Family Social Work, 17(2), pp. 192-201. doi: 10.1111/j.1365-

2206.2012.00832.x.

Stolorow, R.D. and Atwood, G.E. (1996). The Intersubjective perspective, Psychoanalytic Review, 83, pp.181194.

Swanston, J., Bowyer, L., \& Vetere, A. (2014). Towards a richer understanding of school-age children's experiences of domestic violence: the voices of children and their mothers. Clinical Child Psychology and Psychiatry, 19(2), 184-201. doi:10.1177/1359104513485082

Thompson, E. H. and Trice-Black, S. (2012). School-Based Group Interventions for Children Exposed to Domestic Violence. Journal of Family Violence, 27(3), pp. 233-241. doi: 10.1007/s10896-012-9416-6.

Tjersland, O. A., Lindheim, M.O., \& Gudmundson, P.G.M., (2012). A process study of group therapy with children who have been exposed to violence in their family. FOKUS PÅ FAMILIEN, (1):6-26.

Tutty, L. \& Wagar, J. (1994). The evolution of a group for young children who have witnessed family violence. Social Work With Groups, 17(1/2), 89-104.

Ungar, M. (2016). Varied Patterns of Family Resilience in Challenging Contexts. Journal of Family Therapy, 42 (1):19-31.DOI: 10.1111/jmft.12124

Ungar, M. (2011). Community resilience for youth and families: Facilitative physical and social capital in contexts of adversity. Children and Youth Services Review, 33(9), pp. 1742-1748. doi: 10.1016/j.childyouth.2011.04.027.

Van der Kolk, B. (2014). The body keeps the score. New York: Viking. 
Vetere, A. \& Cooper, J. (2005). Children who witness violence at home. In A. Vetere \& E. Dowling (eds). Narrative Therapies with Children and Their Families. London: Routledge

Vetere, A. \& Cooper, J. (2006). The effects of domestic violence on children: Trauma, resilience and breaking the cycle of violence. Journal of Critical Psychology, Counselling and Psychotherapy, 6, pp. 26-38.

Vetere, A. (2012). Supervision and consultation practice with domestic violence. Clinical Child Psychology and Psychiatry, 17, pp. 181-185 DOI: 10.1177/1359104511433563

Westergaard, J. (2009). Effective group work with young people. Berkshire, UK: Open University Press.

White, M. \& Morgan, A. (2006). Narrative Therapy with Children and their Families. Adelaide, South Australia: Dulwich Centre Publications.

White, M. (2004). Working with people who are suffering the consequences of multiple trauma: A narrative perspective. The International Journal of Narrative Therapy and Community Work, 1, pp. 45-76.

Wood, S. L. and Sommers, M. S. (2011). Consequences of intimate partner violence on child witnesses: a systematic review of the literature. Journal of child and adolescent psychiatric nursing: official publication of the Association of Child and Adolescent Psychiatric Nurses, Inc, 24(4), pp. 223-36. doi: 10.1111/j.1744-6171.2011.00302.x.

Yalom, I.D., \& Leszcz, M. (2005). The theory and practice of group psychotherapy. New York: Basic Books.

Zahradnik, M. et al. (2009). Resilience Moderates the Relationship Between Exposure to Violence and Posttraumatic Reexperiencing in Mi'kmaq Youth. International Journal of Mental Health and Addiction, 8(2), pp. 408-420. doi: 10.1007/s11469-009-9228-y. 


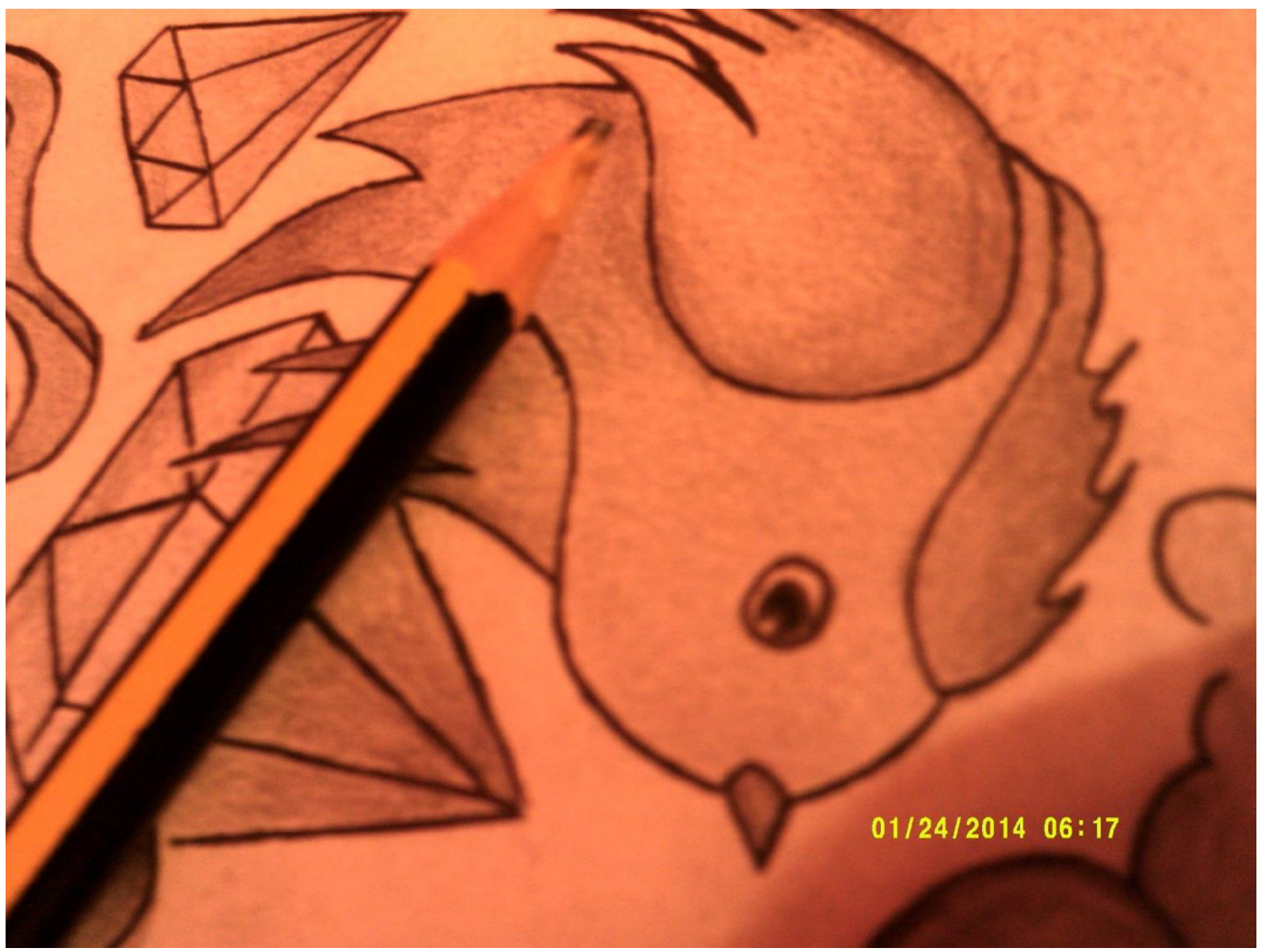

Drawing:

To me it's a way of expressing myself, but with a bit of paper and pencil. All pictures I draw have a meaning to me like the bird I have drawn. To me it means that one day I will be set free from my past and my biggest fears and I'II be able to fly around without being scared of everything including myself. I tend to draw a lot in this massive art book I have, and every drawing means something and it makes me feel better since I know I am also okay at drawing 


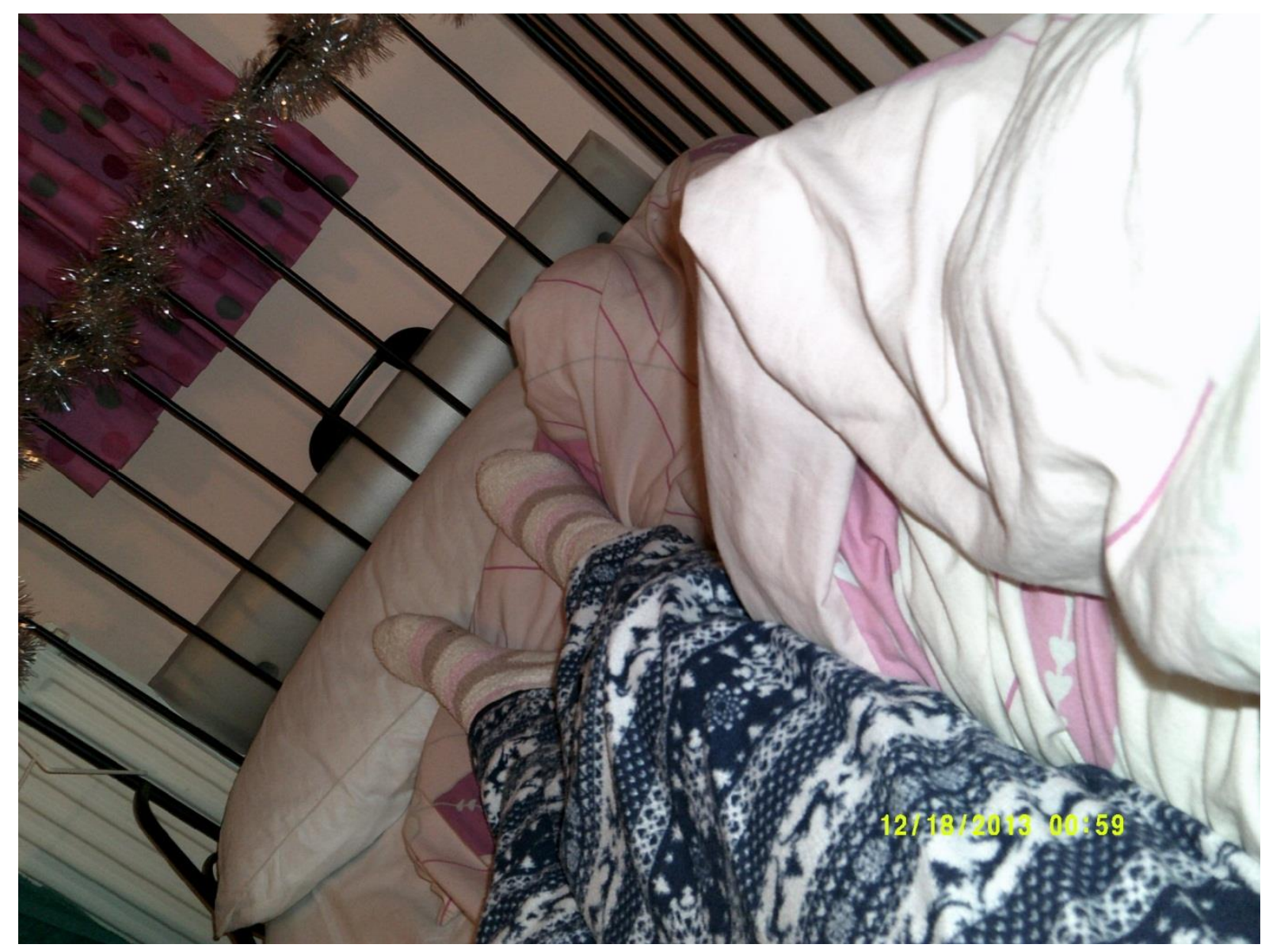

Having my bed helps a lot surprisingly. It has always been somewhere to hide and just let out my emotions. But back then it was a place to hide from him and to play to forget things, it was also a place where my darkest emotions came out. But now, it's the only place I can go and be alone and still, be emotional and just be soothed by its softness and warmth which is something that I don't feel a lot. 
Table 1

Young people who participated in the intervention: Demographic characteristics and attendance patterns

\begin{tabular}{|c|c|c|c|c|c|c|c|c|c|}
\hline Country & Group & $\begin{array}{l}\text { Number of } \\
\text { participants }\end{array}$ & Gender & Age Range & $\begin{array}{l}\text { Mean } \\
\text { Age }\end{array}$ & $\begin{array}{l}\text { Ethnic/National } \\
\text { background }\end{array}$ & $\begin{array}{l}\text { Sessions attended } \\
\text { (range)* }\end{array}$ & $\begin{array}{l}\text { Mean sessions } \\
\text { attended* }\end{array}$ & Dropout \\
\hline Spain & S1 & 9 & $\begin{array}{l}5 \text { Female } \\
4 \text { Male }\end{array}$ & $11-17$ & 13.56 & $\begin{array}{l}8 \text { Spanish } \\
1 \text { South American }\end{array}$ & $6-7$ & 6.89 & 0 \\
\hline Greece & G1 & 9 & $\begin{array}{l}5 \text { Female } \\
4 \text { Male }\end{array}$ & $12-17$ & 13 & $\begin{array}{l}4 \text { Greek } \\
2 \text { Roma } \\
3 \text { Albanian }\end{array}$ & $6-10$ & 8.63 & 1 \\
\hline Greece & $\mathrm{G} 2$ & 8 & $\begin{array}{l}6 \text { Female } \\
2 \text { Male }\end{array}$ & $15-17$ & 16.13 & $\begin{array}{l}4 \text { Greek } \\
3 \text { Albanian } \\
1 \text { Russian }\end{array}$ & $7-10$ & 8.4 & 1 \\
\hline Greece & G3 & 8 & 8 Male & $12-14$ & 12.25 & 8 Greek & $6-8$ & 7.375 & 0 \\
\hline UK & UK1 & 6 & $\begin{array}{l}3 \text { Female } \\
3 \text { Male }\end{array}$ & $11-13$ & 11.83 & 6 White British & $3-10$ & 7.67 & 0 \\
\hline UK & UK2 & 5 & $\begin{array}{l}3 \text { Female } \\
2 \text { Male }\end{array}$ & $15-17$ & 16.2 & 5 White British & $9-10$ & 8.5 & 1 \\
\hline Italy & IT1 & 6 & $\begin{array}{l}4 \text { Female } \\
2 \text { Male }\end{array}$ & $18-19$ & 18.67 & $\begin{array}{l}4 \text { Italian } \\
1 \text { Greek } \\
1 \text { Moldovan }\end{array}$ & 10 & 10 & 0 \\
\hline Italy & IT2 & 7 & $\begin{array}{l}2 \text { Female } \\
5 \text { Male }\end{array}$ & $11-16$ & 12.86 & 7 Italian & 10 & 10 & 0 \\
\hline Totals & & 58 & $\begin{array}{l}28 \text { Female } \\
30 \text { Male }\end{array}$ & & 15.97 & $\begin{array}{l}46 \text { ethnic majority } \\
\text { YP } \\
12 \text { ethnic minority } \\
\text { / migrant YP }\end{array}$ & & 7.96 & 3 \\
\hline
\end{tabular}

*Mean does not include data for young people who dropped out after the first or second session 